Limnol. Rev. (2014) 14, 1: 3-11

DOI 10.2478/limre-2014-0001

\title{
A new water energy dissipater for efficient energy dissipation and enriching the flow with dissolved oxygen content
}

\author{
Mohamed A. Ashour ${ }^{1}$, Tarek Sayed ${ }^{2}$, Salah El-Attar ${ }^{3}$ \\ ${ }^{1,3}$ Department of Civil Engineering, Faculty of Engineering, Assiut University, 71515 Assiut, Egypt, \\ e-mail: mashour475275@yahoo.com (corresponding author) \\ ${ }^{2}$ Department of Civil Engineering, Faculty of Engineering, Assiut University, 71515 Assiut, Egypt, \\ e-mail: tareksayed1986@gmail.com
}

\begin{abstract}
One of the most important problems Egypt is facing nowadays is saving and controlling the limited available quantity of water and its quality for irrigation and other purposes. Such goals may be achieved through different types of diversion head structures across the river and in the entrance of other carrying canals. The construction of diversion head structures, which usually causes many technical problems, should have the objective of solving and overcoming to protect the structure from failure. The main problem occurs downstream. Such structures have the harmful effect of converting the potential energy gained in the upstream side to a kinetic energy in the downstream side. This energy must be dissipated shortly and safely as near as possible to the head structure to avoid its destructive effect. The hydraulic jump is the most effective tool for the dissipation of water energy, accelerating the forming of the hydraulic jump downstream such structures became essential for achieving our main goal. Using energy dissipaters on the soled apron in the downstream side of the structures was the main technique for accelerating the hydraulic jump formation and dissipating great amount of the residual harmful kinetic energy occurring downstream head structures. So early, many researchers investigated different types, shapes, and arrangements of such dissipaters to evaluate its efficiency in dissipating the water energy and accelerating the forming of the hydraulic jump. In fact, in our present study we will try to investigate some other shapes of energy dissipaters, which have not been studied enough, by evaluating its positive technical impact on: (i) percentage value of dissipating kinetic water energy; (ii) percentage value of increasing the dissolved oxygen (DO) content in the irrigation water, and improving its quality. The study is proposed to be held in the irrigation and hydraulic laboratory of the Civil department, Faculty of Engineering, Assiut University, using a movable bed tilting channel $20 \mathrm{~m}$ long, $30 \mathrm{~cm}$ wide, and $50 \mathrm{~cm}$ high, using fourteen types of curved dissipaters with different arrangements as shown in Table 2. It is worth mentioning that, in this first part of our paper, we will introduce a comparative analysis for the efficiency of different types of energy dissipaters available in the literature review. The most effective types of the previously studied dissipaters will be put in a comparison with our new dissipaters from the two above mentioned points of view, and the results will be presented in the second part of this paper later.
\end{abstract}

Key words: energy dissipation, hydraulic jump, curved sill dissipater, water quality, dissolved oxygen.

\section{Introduction}

The several integrated water problems Egypt has been facing in the last two decades became the main challenge the Egyptians have to overcome. First of all, the problem of very limited historical quantity of the river Nile water, in spite of the accelerated increasing of the population, whose life depends mainly on the river Nile, around which all their human activates were established more than 7000 years ago.

Egyptians introduced to the world their outstanding ancient civilization without any tools except the Nile in one of the most arid regions in the world where more than $97 \%$ of its area is dry land, in which the amount of rain does not exceed $150 \mathrm{~mm} \mathrm{yr}^{-1}$ in the north and east shores on the Mediterranean and Red Sea (Korzun 1978; ICCP 2007).

Second, the pollution of irrigation channels water from many resources such as irrigation drainage water, which significantly has a negative impact on the irrigation water quality, and all plants and crops yield, and also animals in turn. 
Third, the decision of Ethiopia to construct an enormous dam on the Blue river (the main source of summer water feeding Lake Nasser in the front of the Aswan High Dam). That dam with such high storage capacity $\left(74 \mathrm{Mm}^{3}\right)$ will decrease seriously the storage capacity of the Aswan High Dam, and the production of electricity, and so prevent the continuity of the developing programs in Egypt in the near and far future as shown in Figure 1, Sutcliffe and Parks (1999) (The dotted curve represents the proposed expected coming flow rate from the Blue Nile after the construction of the Ethiopian dam if the dam reservoir will be filled throughout three years).

In the present study, we will try to test some technical scientific methods for solving some of these constructional and environmental problems. The prime guides in the research are saving, controlling, and improving the quality of the available quantity of water for irrigation. Since saving and controlling of irrigation water can be achieved through storage and diversion head structures like dams, regulators, and weirs, which cause many destructive problems, it must be treated to avoid the probable failure of the head structure. At the same time such structures change the water hydraulic regime behavior owing to raising the upstream water level gaining a great potential energy, which converts into kinetic energy through falling over the head structure.

Such falling and generated kinetic energy and formation of the hydraulic jump in the downstream side must be overcome shortly and as close as possible to the head structure to keep the structure and its soled apron safe.

The most effective method for accelerating the formation of the hydraulic jump to dissipate the falling water residual energy is using some types of energy dissipaters with different shapes and different arrangements on the soled apron in the downstream side of the structure, Habib et al. (2012) and Negm et al. (2003). The literature in such a topic is rich with many studies for many shapes and arrangements of such dissipaters to test the most effective in dissipating the energy downstream the head structures.

This part of the research is focused on the study of the untested shapes of curved dissipaters with different angles of curvature and arrangements from two points of view;

- The first is to examine its efficiency in dissipating the kinetic water energy;

- The second is to examine the most effective shape and arrangement obtained from the above maintained step in enriching the flow with dissolved oxygen for enhancement of the irrigation water quality.

To the best of our knowledge, there are limited references, such as Kucukali and Cokgor (2009), for investigating the problem of dissipating the water energy downstream head structures, and enhancing the water quality by enriching the flow with DO at the same time, as a quality indicator.

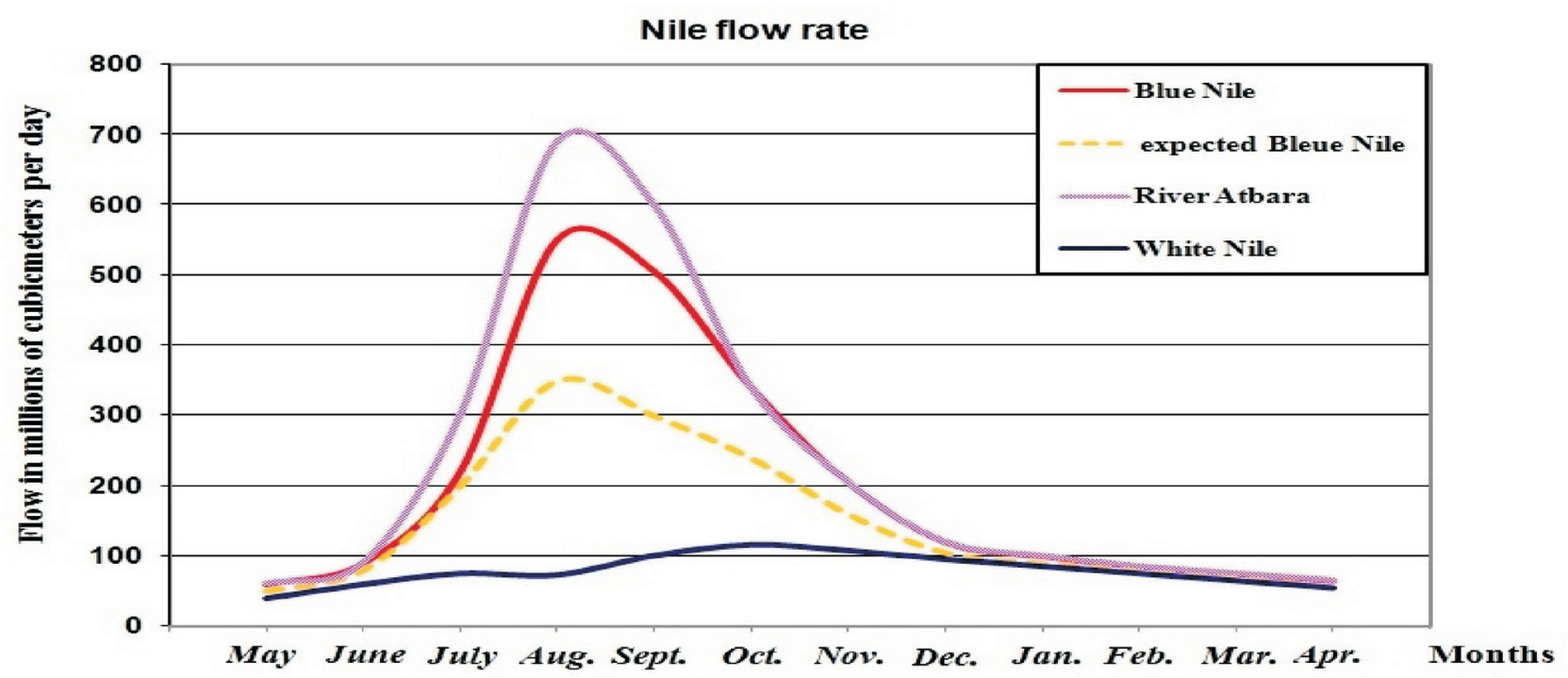

Fig. 1. Flow rate of the Nile 
In this work we will use a curved sill dissipater with different angles of curvature, in the direction of the flow and in the opposite direction, as one continuous row or more or as staggered separate dissipaters in one or more rows, to examine its efficiency in dissipating water energy, and at the same time its role in enriching the flow with oxygen through the great aeration of the flow within the dissipating energy distance downstream head structure.

On the light of the complicated and serious water situation in Egypt after the beginning of the construction of the so called Grand Ethiopian Renaissance Dam on the Blue Nile, the historical Egyptian share of the Nile water will significantly decrease, in the time of the vital request of Egypt to increase its share of the Nile water.

The main aim of this research is to introduce simple practical equations to help designers of irrigation structures to fix the percentage of energy dissipation at any distance downstream the head structure and at the same time to know the percentage of DO gained in the water flow through such a distance.

\section{Why such topic attracted our attention?}

Simply the first and logical step to solve our water problems is to optimize our use of water to the maximum possible efficiency quantitatively and qualitatively. This may be achieved through the construction of many diversion head structures to divert and transport the water to some new lands. Also we may reuse the drainage water once again in the irrigation process after improving its quality to meet the specifications of the proper irrigation water.

The present discussion of this paper has led us to the urge of studying the safety of such diversion head structures, and improving the water quality at the same time. This may be achieved through using some types of energy dissipaters, which serve effectively in both the under study problems

In this paper, we will review the different types of energy dissipaters used downstream head structures and introduce a comparative analysis for the efficiency of each type in dissipating the residual energy downstream diversion, head structures. In the second part of this paper we will try to introduce our new type of such dissipaters with different arrangements. Also, for the first time, the effect of the new investigation introduced types of dissipaters on the water quality through enhancing the dissolved oxygen content in the flowing irrigation water.

\section{Literature Review}

Energy dissipation. All of the available evaluations of energy dissipaters stemmed from experimental and field observations made on regular (straightedged) dissipaters. Such previous studies include those of Alikhani et al. (2010), Habib et al. (2012), Negm et al. (2003) and Tiwari et al. (2011). They found that, sills or blocks were used in stilling basins to increase the rate of energy dissipation and to reduce the bed velocity in the region of the hydraulic jump. Also, the effect of the sill on the jump characteristics depends on factors such as the sill configuration, sill location and sill spacing when more than one sill was used.

Wafaie (2001a, 2001b) investigated experimentally the free rectangular hydraulic jump phenomenon on roughened channel bed with dentated, solid, zigzagged bed sills, under different flow conditions, different bed sill heights, and different bed sill locations. Statistical analysis for the experimental results was made to obtain the best height and location of the bed sill. It was found that, the optimum relative height of the used bed sill $\left(h_{s} / B\right)$ is 0.11 . In addition the optimum relative position of the used bed sill $(L / B)$ is 5.83 .

To the best of our knowledge, there are little attempts on using energy dissipaters with curved upstream edges such as Murthy and Divatia (1982) and El-Gawhary et al. (1986), who experimented a circular curved end sill of specified diameter and height with narrow range of discharges in a small laboratory flume. Another study was done by Eloubaidy et al. (1999), who investigated experimentally the effect of relative size, curvature and location of curved floor baffle blocks in the dissipation of energy and control of hydraulic jump. The results have indicated that, for all flow conditions, the curved blocks are (3.2-33.3\%) more effective in lowering the downstream kinetic energy than regular straight edge blocks. In addition, the curved blocks provided better stability to the hydraulic jump. Bestawy (2013) studied 14 different models of baffle piers to introduce a shape of baffle pier, which had maximum energy dissipation. The results showed that the vertical semi-circular section (model No. 7) as shown in Figure 2, has the greatest effect among other tested models for dissipating water energy.

Different types of basins have been studied by the United States Bureau of Reclamation (USBR) and its performance has been classified by Peterka (1983). Also, a comparison between USBR and expanding stilling basins was carried out based on the relative energy loss $\left(\Delta E / E_{1}\right)$. Figure 3 shows the relation be- 


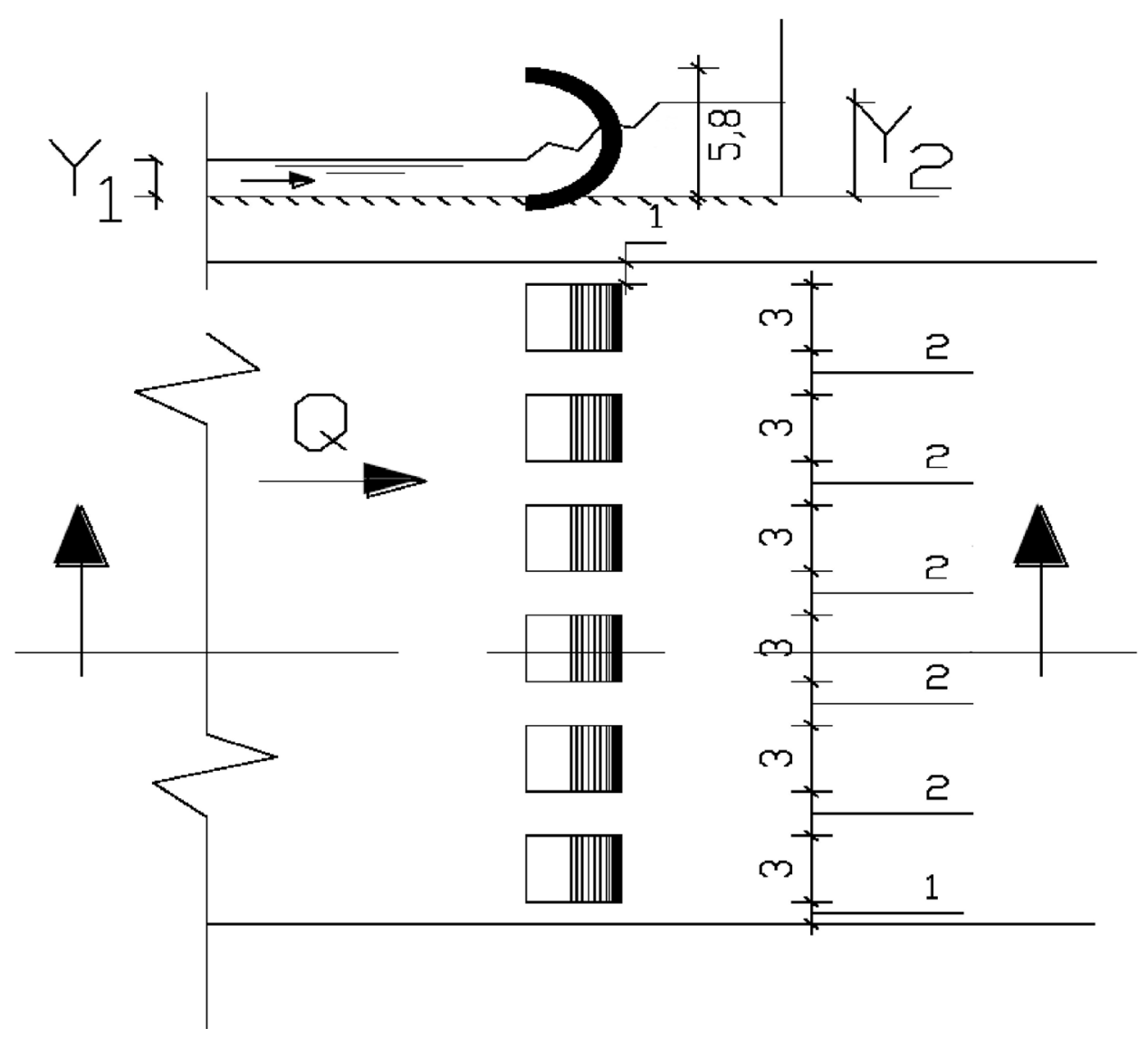

Fig. 2. Tested model No. 7 of baffle piers, Bastawy (2013)

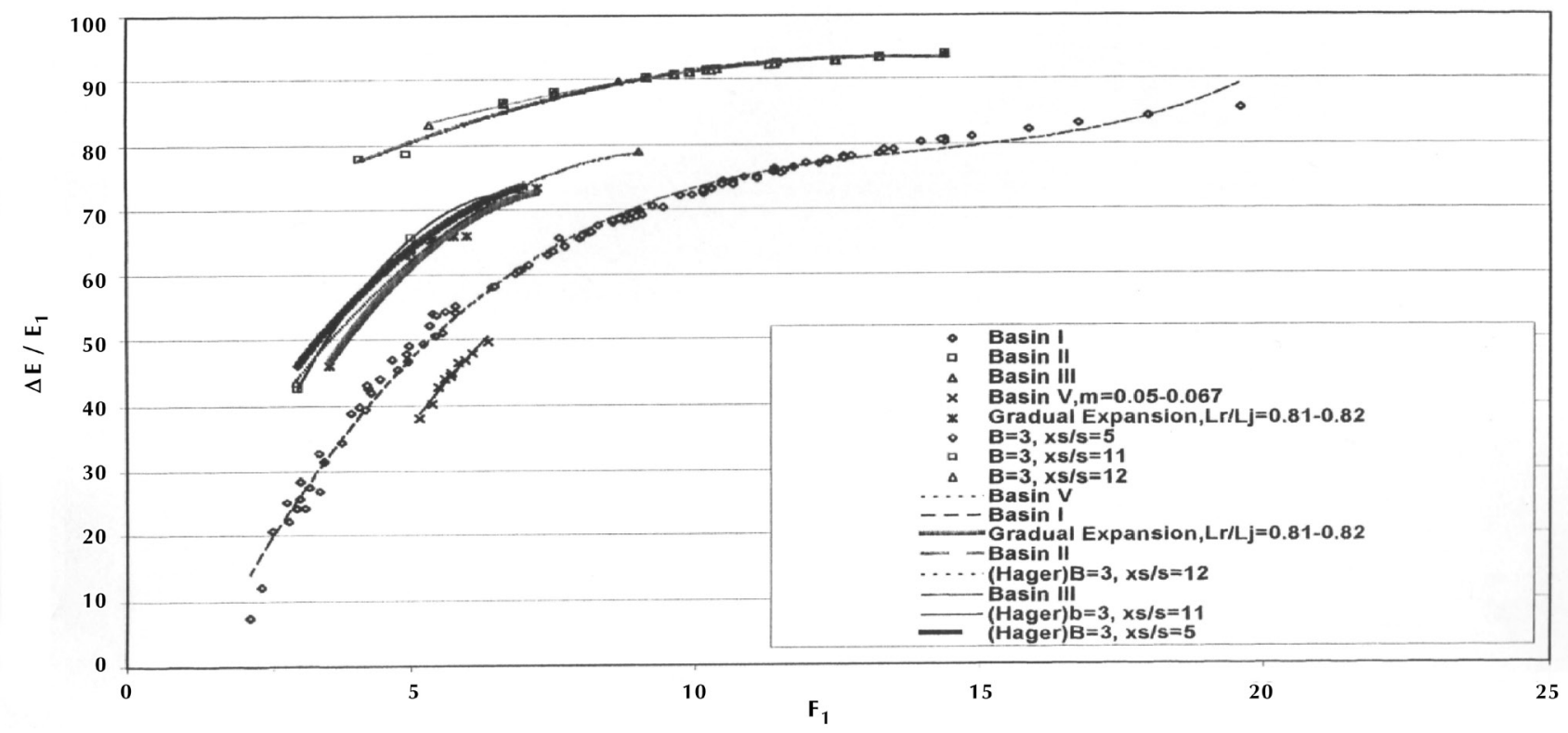

Fig. 3. Relation between the relative energy loss of the jump and the initial Froude number for the stilling basins included in the comparison, Peterka (1983) 
tween energy loss and initial Froude number for all basins. The figures indicate that:

- The USBR basins II and III gave the maximum energy loss while USBR basin V gave the least energy loss,

- Both the gradually expanding and sill controlled abruptly expanding stilling basins were nearly equal in dissipating energy.

To make a comparison between the results of the different equations obtained by different researchers used to estimate the relative energy loss, the following values of the most effective parameters were assumed to estimate the relative energy loss:

$F_{e 1}=6.0 ; h_{s} / B=0.11 ; h_{s} / y_{1}=2.0 ; r_{0}=r_{2} / r_{1}=1.30$

Table 1 introduce a compact summary of the most popular methods investigated by many authors and their predicted relations and equations for determining the energy dissipation percentage. For the comparison purpose, the last column of Table 1 presents the calculated percentage value of the energy dissipated according to each of the tabulated authors. From such an introduced comparative analysis, it is clear that Habib (2012), Habib et al. (2003) and Wafaie (2001a) are the most efficient methods in dissipating residual water energy downstream head structures. While Negm et al. (2003), Rageh (1999) and Shahmirzadi et al. (2012) are the lowest methods. The calculations showed that, the energy dissipation efficiency percentages for the first three mentioned studies were between $13.45 \%, 30.12 \%$; at the same time the least values of the energy dissipation efficiency percentages in the above mentioned studies were between $1.90 \%$, $3.50 \%$ which is much less than others.

As it can be seen from equation 1 proposed by Habib et al. (2003), guide walls represent an obstruction in the basin so they improve the characteristics of the hydraulic jump (reduce the depth and the length and increase the energy loss). So they can be used for the design of stilling basin.

Table 1. The most popular investigated methods for water energy dissipation downstream head structures and comparative analysis of its efficiency in dissipating the water kinetic energy

\begin{tabular}{|c|c|c|c|c|c|}
\hline References & Equation & Definition sketch & \begin{tabular}{|c|} 
Shapes \\
of energy \\
dissipaters
\end{tabular} & $\begin{array}{l}\text { Computed } \\
\text { energy } \\
\text { dissipation }\end{array}$ & \begin{tabular}{|c|} 
Energy \\
dissipation \\
efficiency
\end{tabular} \\
\hline Habib et al. (2012) & $\Delta E / E_{1}=\frac{r_{0}^{2} d_{o}^{2}\left(2+F_{e_{1}}^{2}-2 d_{o}\right)-F_{e_{1}}^{2}}{r_{0}^{2} d_{o}^{2}\left(2+F_{e_{1}}^{2}\right)}$ & 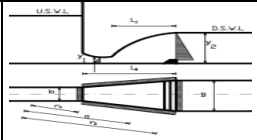 & & $\begin{array}{l}\left(\Delta E / E_{l}\right)_{h s / y l=0}=0.599 \\
\left(\Delta E / E_{l}\right)_{h s y l=2}=0.623\end{array}$ & $4.10 \%$ \\
\hline Habib (2012) & $\Delta E / E_{1}=1-\left[\frac{D_{0}^{2}\left(Z+D_{o}\right)\left(e+2 C^{* *}\right)^{2}+0.5 F_{e_{1}}^{2}}{D_{0}^{2}\left(1+0.5 F_{e_{1}}^{2}\right)\left(e+2 C^{* *}\right)^{2}}\right]$ & & & $\begin{array}{l}\left(\Delta E / E_{l}\right)_{h s / y l=0}=0.581 \\
\left(\Delta E / E_{l}\right)_{h s y l=2}=0.756\end{array}$ & $30.12 \%$ \\
\hline Habib et al. (2003) & $\Delta E / E_{1}=1-\frac{\left[y_{r}+\frac{0.5 F_{e_{1}}^{2}\left(b / y_{1}\right)^{2}}{\left(b / y_{1}\right)^{2} y_{r}^{2}+0.5\left(b / y_{1}\right)^{3}+0.0625 y_{r}^{4}}\right]}{\left(1+0.5 F_{e_{1}}^{2}\right)}$ & $\frac{2}{4}$ & & $\begin{array}{l}\left(\Delta E / E_{1}\right)_{h s / y l=0}=0.474 \\
\left(\Delta E / E_{1}\right)_{h s y l=2}=0.538\end{array}$ & $13.45 \%$ \\
\hline Negm et al. (2003) & $\Delta E / E_{1}=-0.973-0.153 F_{e_{1}}+1.031 F_{e_{1}}^{2}+0.006 h_{s} / y_{1}$ & & & $\begin{array}{l}\left(\Delta E / E_{l}\right)_{h s y l=0}=0.634 \\
\left(\Delta E / E_{l}\right)_{h s y l=2}=0.646\end{array}$ & $1.90 \%$ \\
\hline Rageh (1999) & $\Delta E / E_{1}=1-\left(\frac{F_{e_{1}}+2 r_{o} y_{o}}{r_{o} y_{o}\left(F_{e_{1}}+2\right)}\right)$ & $\frac{1}{2 x+2}$ & & $\begin{array}{l}\left(\Delta E / E_{1}\right)_{h s y l=0}=0.651 \\
\left(\Delta E / E_{1}\right)_{h s y l=2}=0.673\end{array}$ & $3.50 \%$ \\
\hline Shahmirzadi et al. (2012) & $\Delta E / E_{1}=\left[\left(\frac{V_{0}^{2}}{2 g}+y_{3}\right)-\left(\frac{V_{5}^{2}}{2 g}+y_{5}\right)\right] /\left(\frac{V_{0}^{2}}{2 g}+y_{3}\right)$ & & & $\begin{array}{l}\left(\Delta E / E_{1}\right)_{h s y l=0}=0.880 \\
\left(\Delta E / E_{1}\right)_{h s y l=2}=0.903\end{array}$ & $2.75 \%$ \\
\hline Wafaie (2001a) & $\Delta E / E_{1}=\left(A_{E} \times F_{e_{1}}^{2}\right)+\left(B_{E} \times F_{e_{1}}\right)+C_{E}$ & & & $\begin{array}{l}\left(\Delta E / E_{1}\right)_{h s y l=0}=0.548 \\
\left(\Delta E / E_{1}\right)_{h s y l=2}=0.657\end{array}$ & $19.84 \%$ \\
\hline
\end{tabular}




$$
\Delta E / E_{1}=1-\frac{\left[y_{r}+\frac{0.5 F_{e q}^{2}\left(b / y_{1}\right)^{2}}{\left(b / y_{1}\right)^{2} y_{r}^{2}+0.5\left(b / y_{1}\right)^{3}+0.0625 y_{r}^{4}}\right]}{\left(1+0.5 F_{q_{1}}^{2}\right)}
$$

From the percentage value of the energy dissipated, according to each of the mentioned previous studies included in the last column of our comparative Table 1, it is clear that, Eloubaidy et al. (1999), Tiwari et al. (2011) and Wafaie (2001a, 2001b) are the most efficient methods in dissipating residual water energy downstream head structures. So, in the present study we will examine curved sill dissipaters with different angles of curvature, and different arrangements in the flow direction, and in the opposite direction. We will keep the relative height $(h / B)$ constant at the value 0.11 as recommended by Wafaie (2001a) and the relative position $\left(L_{s} / B\right)$ at the value 5.83 as recommended by Wafaie (2001b). At the same time, we will keep the sloped upstream face of the sill dissipater constant at (1:1) as recommended by Tiwari et al. (2011).

Irrigation water quality. The challenge of improving irrigation water quality is a growing global concern, because of the accelerated shortage of the available fresh water. On the light of this fact, we have to reuse the drainage water once again in irrigation process after mixing it with the suitable percentage of irrigation water. To keep such mixed water within the safe specification of the irrigation water, the added drainage water must be treated for improving its quality. The DO content is a significant indicator for the suitability of the water for the irrigation and agricultural activates, because DO is one of the most important water quality parameters affecting the quality of water and wastewater. Also, both aquatic plants and animals depend on DO for survival. The irrigation or agricultural activates need water (around $5 \mathrm{mg} \mathrm{dm}^{-3}$ of DO).

In this study we will try to test the new introduced type of the most effective energy dissipaters in the enrichment of the flow with Dissolved Oxygen along the stilling basin downstream head structures.

The dissolved oxygen content is a significant indicator for the aeration of the water. Enhancing the water DO content through the aeration is extensively studied in the literature review (Gameson 1957; Avery and Novak 1978; Nakasone 1987). Another study done by Kibel and Coe (2009) tested the effect turbine of in- stallation on dissolved oxygen concentrations within the weir pool.

The study done on the direct effect of hydraulic structures on dissolved oxygen concentrations was the study done by El Baradei (2013). However, this study investigated the effect of gates on the DO concentration. El Baradei (2013) studied the effect of broad crested trapezoidal weirs on the dissolved oxygen concentration at two different water depths. Results showed that installing the weir increased the values of the DO (comparing its upstream side with the downstream side) by an average of 5.3\% comparing all depths. It was also found that installing a weir on a river will result in shortening the time the DO takes to recover after a pollutant was dropped in a river by $39.5 \%$.

Reviewing the literature review concerning the enhancement of the DO content, proved that very limited researches join the energy dissipation and the flow enrichment with the dissolved oxygen for improving the quality of water. Kucukali and Cokgor (2009) found that the hydraulic jump aeration efficiency has linear relationship with the energy dissipation rate for unit width of the channel as follows:

$E_{20}=0.0115 \omega+0.01$

where: $\omega$ is the energy dissipation rate per unit channel width $\left(\mathrm{W} \mathrm{m}^{-1}\right)$.

To the best of our knowledge, no studies had been done for joining the shape of the energy dissipaters downstream water structures and the gained quantity of DO, and so improving the irrigation water quality.

The results of the study will be presented in the second part of that paper later.

\section{Theoretical approach}

The formation of the hydraulic jump in the downstream side must be overcome shortly and as close as possible to the head structure to keep the structure and its soled apron safe. Using energy dissipaters on the soled apron in the downstream side of the structures was the main technique for accelerating the hydraulic jump formation and dissipating great amount of the residual harmful kinetic energy occurring downstream head structures.

Referring to Figure 4, the following functional form for the dissipation energy in rectangular basin with curved sill dissipaters could be expressed as follows: 


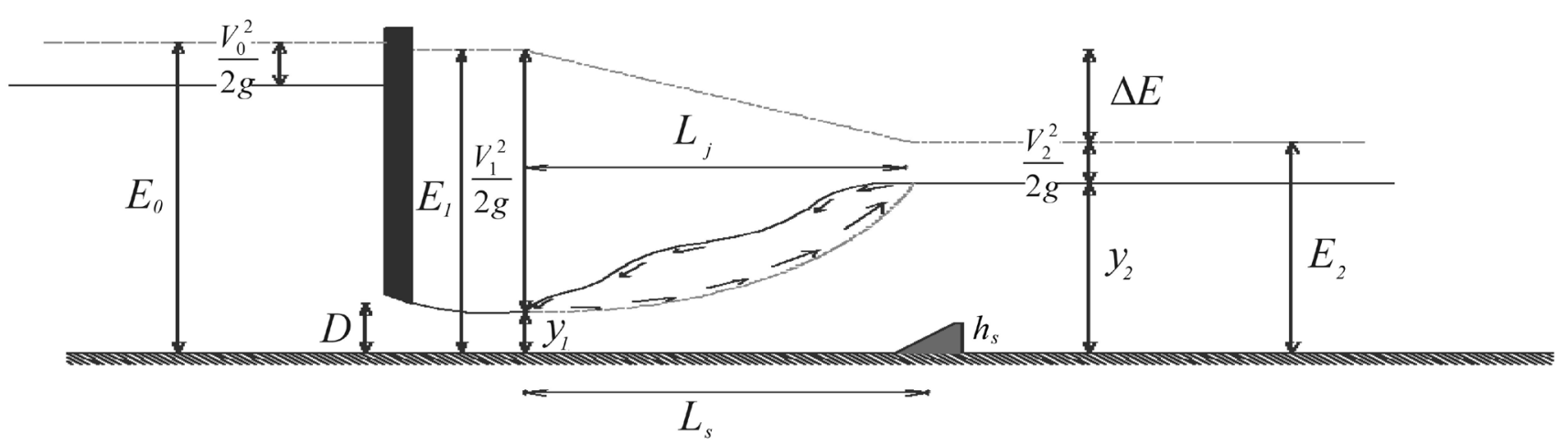

Fig. 4. Definition sketch for forced hydraulic jump with curved end sill

$$
\Delta E=\phi\left(\rho, \mu, g, D, y_{1}, y_{2}, L_{W}, L_{j}, L_{S}, h_{s}, \theta, q\right)
$$

Using the dimensional analysis principle based on the three repeating variables $\rho, g$ and $y_{1}$, Equation 3 becomes:

$\frac{\Delta E}{y_{1}}=\phi\left(\frac{y_{2}}{y_{1}}, \frac{D}{y_{1}}, \frac{L_{w}}{y_{1}}, \frac{L_{j}}{y_{1}}, \frac{L_{s}}{y_{1}}, \frac{h_{s}}{y_{1}} \frac{1}{\theta}, F_{e_{1}}, R_{e_{1}}\right)$

In Equation 4, the effect of $R_{e 1}$ is neglected as the viscosity has a negligible effect on the hydraulic jump characteristics in the present study because the temperature will be fixed during the course of the experimental work. Also, $L_{s} / y_{1}$ and $h_{s} / y_{1}$ are constant because the position and the height of the sill will be fixed. Equation 4 becomes:

$$
\frac{\Delta E}{y_{1}}=\phi\left(\frac{y_{2}}{y_{1}}, \frac{L_{j}}{y_{1}}, \frac{L_{w}}{y_{1}}, \theta, F_{e_{1}}\right)
$$

\section{Program of experimental work}

Experiments will include the testing of the following tabulated curvature angles of the dissipater sills, its arrangements and its curvature direction with respect to the main flow direction (Table 2).

The above table shows the proposed different tested dissipater sills downstream the head structures (shapes, arrangements, and direction of curvature with respect to the main flow direction).

The comparison will be done between the results of the above mentioned arrangements to get the most effective one in dissipating the water energy, and then experiments will be carried out to examine its efficiency in enriching the flow with oxygen, and so improving the quality of the irrigation water.

\section{Conclusions}

From the present study which reviewed the characteristics and efficiency of different types of dissipaters and stilling basins, a comparative study was done, from which we can conclude the following main points:

1. The USBR basins II and III gave the maximum energy loss while USBR basin V gave the least energy loss.

2. Both the gradually expanding and sill controlled abruptly expanding stilling basins were nearly equal in dissipating energy.

3. The gradually expanding basin requires minimum tail water depth, while the USBR basin $\mathrm{V}$ requires maximum tail water depth.

In addition to that, our comparative study for the stilling basins with roughness bed, sills and steps showed that:

4. The roughness elements considerably reduce the sequent depth and length of the hydraulic jump.

5. The staggered roughness is more efficient than strip roughness.

6. Increasing the roughness length does not make great difference in energy loss.

7. Sill height and position have a considerable effect on the sequent depth ratio and shorten the length of the basin, which would consequently reduce costs.

8. The most efficient methods in dissipating residual water energy downstream head structures were that examined by Habib (2012), Habib et al. (2003) and Wafaie (2001a). While the lowest efficient methods were that examined by Negm et al. (2003), Rageh (1999) and Shahmirzadi et al. (2012). The energy dissipation efficiency of the first three methods was between $30.12 \%$ and $13.45 \%$, while the efficiency of the last three methods was between $3.50 \%$ and $1.90 \%$. 
Table 2. The tested configurations of curved sill dissipaters

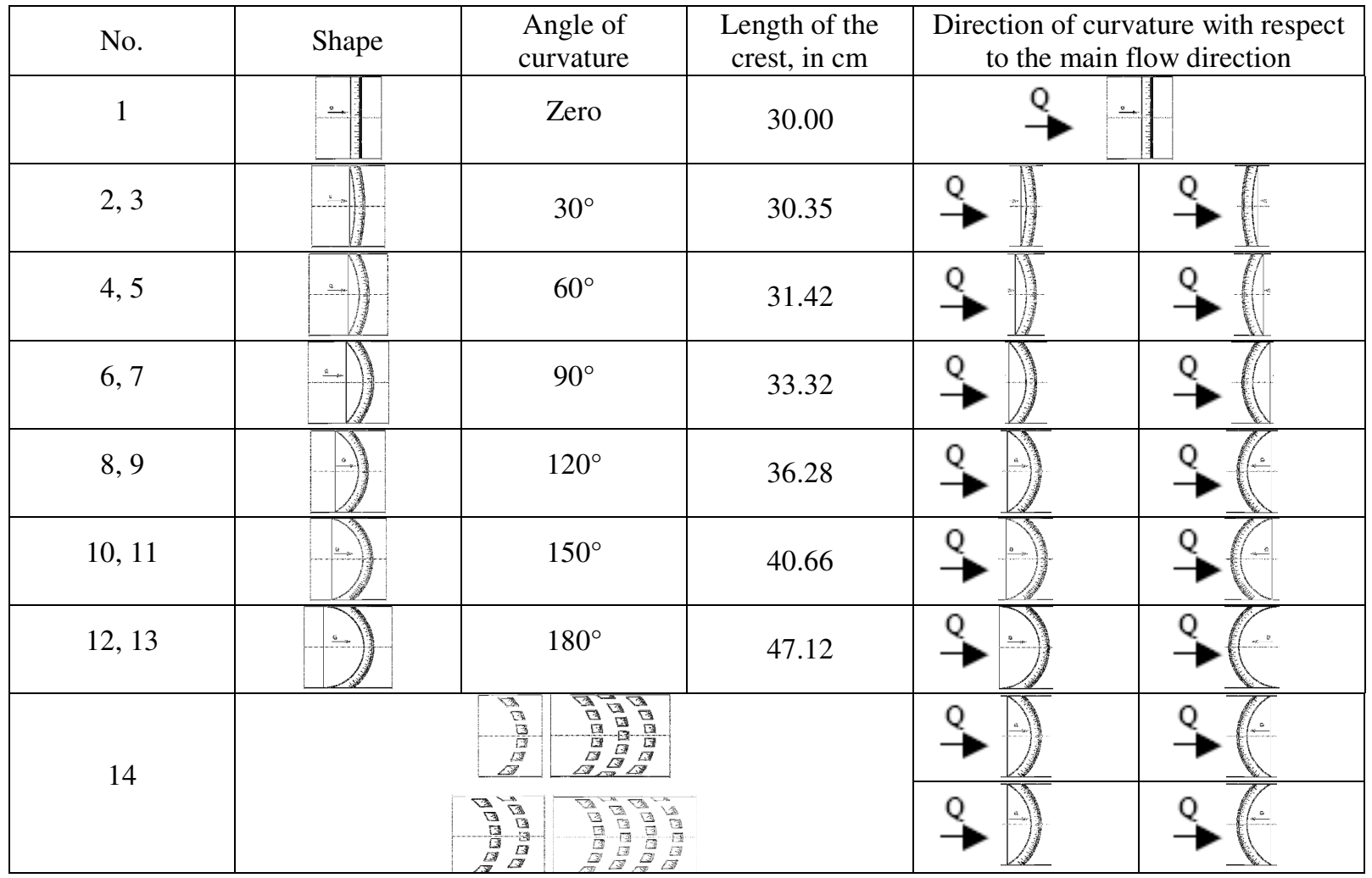

9. Since the Dissolved Oxygen content is a significant indicator for the suitability of the water for the irrigation and agricultural activates, we will try to test the most effective energy dissipaters in enrichment of the flow with Dissolved Oxygen along the stilling basin downstream head structures.

\section{Nomenclature}

The following symbols are used in this paper:

$q$ discharge per unit width of the flume;

$R_{e 1} \quad$ Reynolds number upstream the jump;

$r_{1} \quad$ radius at the beginning of the jump;

$r_{2} \quad$ radius at the end of the jump;

$r_{0} \quad$ ratio of $r_{2}$ to $r_{1}$

$S_{0} \quad$ bed slope of the channel;

$z \quad$ height of drop;

$\rho \quad$ density of the water;

$\mu \quad$ dynamic viscosity of the water;

$\theta \quad$ end sill angle of curvature

$B \quad$ width of the flume;

$b \quad$ contracted width of the channel

$D$ gate opening;

DO dissolved oxygen;

$E_{0} \quad$ total flow of energy upstream the sluice gate;

$E_{1} \quad$ total flow of energy upstream the jump;

$V_{0} \quad$ average velocity upstream the sluice gate;

$V_{1} \quad$ average velocity at the initial depth;

$V_{2}$ average velocity at the sequent depth;

$y_{1} \quad$ initial depth of jump;

$y_{2} \quad$ sequent depth of jump;

$y_{c} \quad$ sequent depth of jump;

$E_{2}$ total flow of energy downstream the jump;

$\Delta E$ energy loss;

$F_{e 1} \quad$ Froude number upstream the jump;

$g$ gravitational acceleration;

$h$ seight of the end sill;

$L_{B} \quad$ length of stilling basin;

$L_{j} \quad$ length of jump;

$L_{s} \quad$ position of end sill from the gate;

$L_{w} \quad$ length of the crest 


\section{References}

Alikhani A., Behrozi-Rad R., Fathi-Moghadam M., 2010, Hydraulic jump in stilling basin with vertical end sill, Int. J. Phys. Sci. (IJPS) 5(1): 25-29.

Ashour M.A.,1979, Aeration of the flow with dissolved oxygen \& dissipating water energy in shooting flow, PhD. thesis, Moscow Institute of Strucutral Engineering.

Avery S., Novak P, 1978, Oxygen transfer at hydraulic structures, J. Hydraul. Eng. 104(11): 1521-1540.

Bestawy A., 2013, New shapes of baffle piers used in stilling basins as energy dissipators, Asian Trans. Eng. (ATE) 3(1): 1-7.

El Baradei S.A., 2013, Saving on energy of and determining the best location of water treatment plant along rivers depending on the effect of broad crested weir on dissolved oxygen concentrations in water, J. Clean Energy Technol. 1(3): 202-205.

El Baradei S.A., 2011, Effect of free hydraulic jump on dissolved oxygen concentrations in water at different vertical control gate openings, ICASTOR Journal of Engineering 14(3): 281-291.

El-Gawhary E.L., Soliman M.A., Hamed M.E., Zaghlor Y., 1986, Characteristics of flow near concave obstacles, Civil Engineering Research Magazine (CERM), A1-Azhar University 8(1).

Eloubaidy A.F, Al-Baidhani J.H., Ghazali A.H., 1999, Dissipation of hydraulic energy by curved baffle blocks, Pertanika J. Sci. Technol. 7(1): 69-77.

Gameson A., 1957, Weirs and aeration of rivers, J. Inst. Water Eng. 11(5): 477-490.

Habib A.A., 2012, Study of free flow blow vertical sluice gate with positive step in redial stilling basin, Egyptian Int. J. Eng. Sci. Technology 15(1).

Habib A.A., Abdel-Azim M.A, Abd-Allh Y.M., Saleh Y.K., 2012, Estimation of hydraulic jump characteristics in stilling basin with guide walls, J. Eng. Sci. (JES) Assiut University, 40(6):1599-1609.

Habib A.A., Abdel-Aal G.M., Negm A.M., Owais T.M., 2003, Theoretical modeling of hydraulic jumps in radial stilling basins ended with sills, Proc. of the 7th Int. Water and Technology Conference (IWTC), Cairo: 619-631.

[IPCC] Intergovernmental Panel on Climate Change, 2007, Observations: Surface and Atmospheric Climate Change, [in:] Solomon S., Qin D., Manning M., Chen Z., Marquis M., Averyt K.B., Tignor M., Miller H.L. (eds.), Climate Change 2007: The Physical Science Basis. Contribution of Working Group I to the Fourth Assessment Report of the Intergovernmental Panel on Climate Change, Cambridge Univ. Press, Cambridge-New York: 235-336.
Kibel P., Coe T., 2009, Castleford mill hydro power proposal. River Aire - fisheries assessment, Fishtek Consulting, Devon, p. 33.

Korzun V.I. (ed.), 1978, World water balance and water resources of the earth. Studies and Reports in Hydrology. Vol. 25, Unesco, Paris, p. 663.

Kucukali S., Cokgor S., 2009, Energy concept for predicting hydraulic jump aeration efficiency, J. Environ. Eng. 135(2): 105-107.

Murthy Y.K., Divatla E., 1982, Behaviour of stilling basins in large spillways, Irrigat. Power 39(2).

Nakasone H., 1987, Study of aeration at weirs and cascades, J. Environ. Eng. 113(1): 64-81.

Negm A.M., Abdel-Aal G.M., Habib A.A.,Owais T.M., 2003, Effect of end sill in radial basin on characteristics of free hydraulic jumps, Proc. of the 1st Int. Conf. of Civil Engineering Science (ICCESI). Vol. 1, Cairo: p. 12.

Peterka A.J., 1983, Hydraulic design of stilling basin and energy dissipators, Eng. Monograph 25, U.S. Bureau of Reclamation (USBR), Denver, p. 221.

Rageh O.S., 1999, Effect of baffle blocks on the performance of radial hydraulic jump, Proc. of the 4th International Water Technology Conference (IWTC), Alexandria: 255-269.

Shahmirzadi M., Sumi T., Kantoush S., 2012, The effect of end-sill geometry on functionality of In-ground stilling basin, Annuals Disas. Prev. Res. Inst., Kyoto Univ. 55(2): 561-570.

Sutcliffe J.V., Parks Y.P., 1999, The hydrology of the Nile, IAHS Special Publication No. 5, IAHS Press, Wallingford, p. 179.

Tiwari H.L, Goel A., Gahlot V.K., 2011, Experimental study of effect of end sill on stilling basin performance, Int. J. Eng. Sci.Technol. (IJEST) 3(4): 3134-3140.

Wafaie E.M., 2001a, Optimum height for bed sills in stilling basins, Bull. Faculty Eng. Assiut University 29(1): 1-12.

Wafaie E.M., 2001b, Optimum location for bed sills in stilling basins, Bull. Faculty Eng. Assiut University 29(1): 13-24. 